Aletria, Belo Horizonte, v. 28, n. 3, p. 83-102, 2018

\title{
Nação, raça e identidade em Poems on Various Subjects, Religious and Moral, de Phillis Wheatley
}

\section{Nation, Race and Identity in Poems on Various Subjects, Religious and Moral, by Phillis Wheatley}

José de Paiva dos Santos

Universidade Federal de Minas Gerais, Belo Horizonte, Minas Gerais / Brasil josedepaivasantos@gmail.com

Resumo: Este artigo discute alguns poemas da escritora afro-americana Phillis Wheatley, publicados em Poems on Various Subjects, Religious and Moral, no contexto dos debates em pauta no século XVIII acerca da humanidade dos negros. $\mathrm{O}$ argumento principal é que, embora sutil em suas observações devido a sua posição social frágil, Wheatley faz uso da poesia para confrontar interpretações racistas de textos bíblicos, bem como de teorias pseudocientíficas que visavam caracterizar o sujeito negro como intelectualmente e culturalmente inferior ao euro-americano. A análise demonstra que Wheatley se posiciona com autoridade diante dessas afirmações, tornando-se assim precursora de movimentos de vindicação da cultura negra que ganhariam proeminência mais tarde em narrativas autobiográficas de escravos, sermões, canções folclóricas e ensaios abolicionistas. As reflexões sobre raça, religião, nação e cidadania que norteiam a análise se baseiam, principalmente, em teorizações desenvolvidas por Henry Louis Gates, Jr., Eddie S. Glaude, Jr. e Joanna Brooks.

Palavras-chave: Wheatley; vindicação; Iluminismo; Protestantismo; Cristianismo.

Abstract: This article examines a few poems by the African-American writer Phillis Wheatley, published in Poems on Various Subjects, Religious and Moral, against the backdrop of the debates on the humanity of black people that took place in the eighteenth century. The main argument is that, although subtle in her remarks due to her fragile social position, Wheatley makes use of her poetic voice to challenge racist interpretations of the biblical text, as well as pseudoscientific theories which categorized 
black individuals as intellectually and culturally inferior compared to Euro-Americans. This paper demonstrates that Wheatley positions herself firmly against such charges, thereby becoming the precursor of black vindication movements that would gain prominence later in slave narratives, sermons, folk songs, and pro-abolition essays. The considerations on race, religion, nation and citizenship that guide the analysis benefit from theorizations by Henry Louis Gates, Jr., Eddie S. Glaude, Jr. and Joanna Brooks.

Keywords: Wheatley, vindication, Enlightenment, Protestantism, Christianity.

\section{Introdução}

Estudiosos da literatura afrodescendente consideram a coletânea de poemas intitulada Poems on Various Subjects, Religious and Moral, da escritora afro-americana Phillis Wheatley, um dos grandes feitos literários do século XVIII nos Estados Unidos. Esta conquista se deve tanto às circunstâncias históricas nas quais a autora escreveu quanto às dificuldades que enfrentou para ver sua obra publicada. Wheatley foi trazida aos Estados Unidos como escrava ainda criança, por volta dos sete anos de idade. Seus captores estimavam que tivesse nascido em 1753. Como a longa viagem havia deteriorado sua saúde, de forma que havia perdido o valor comercial, ela foi vendida por um preço irrisório a John Wheatley, um rico mercador de Boston que, no momento, procurava uma escrava para ajudar sua esposa nos trabalhos domésticos. Sendo que seu verdadeiro nome thes era desconhecido, os Wheatleys the deram o nome de Phillis, o mesmo do navio no qual havia sido transportada. Desde o início, o que mais chamou a atenção da família foi a rapidez com que ela aprendeu a língua inglesa, fato que levou a família a estimulá-la a ler a Bíblia. Ao ver o casal de filhos da família manuseando a pena de escrever, logo começou a imitá-los, de forma que o aprendizado da escrita foi sem esforço. Após isso, com o apoio do casal de filhos, veio o estímulo para ler autores clássicos da literatura ocidental - Thomas Gray, Alexander Pope, John Milton, dentre outros. A destreza da jovem escrava com as palavras surpreendeu enormemente a vizinhança e a igreja à qual os Wheatleys pertenciam. Em pouco tempo, influenciada pelo estilo poético clássico e pelas leituras da Bíblia, ela começou a escrever poemas. Aos 18 anos, em 1772, ela já havia composto cerca de 18.

Embora tivesse o total apoio da família à qual pertencia, incentivo incomum entre os donos de escravos, o mesmo não aconteceu na hora 
de encontrar recursos para publicação de seus escritos. Apesar de ter publicado, com a ajuda da família Wheatley, poemas avulsos em panfletos em Boston, o sonho de publicar uma coletânea ainda estava distante. $\mathrm{O}$ ceticismo imperava em relação à possibilidade de uma jovem escrava ser capaz de produzir versos, ainda mais no estilo clássico, semelhantes aos grandes poetas europeus. A descrença era tanta que uma banca de avaliação foi montada para verificar as pretensões literárias da jovem escritora. Nessa banca, explica o crítico Henry Louis Gates Jr., estavam presentes 18 dignitários da colônia de Massachusetts. O que estava em jogo não era apenas a cor da jovem, mas sua capacidade de raciocínio e suas habilidades artísticas, já que o pensamento da época era que negros eram incapazes de atividades intelectuais. A pergunta que queriam responder era: seria uma jovem africana capaz de produzir poemas no mesmo nível dos grandes nomes da tradição poética? Na reunião estavam presentes o governador de Massachusetts Thomas Hutchinson, reverendo Mather Byles, teólogo e poeta, Joseph Green, um conhecido satirista, dentre outros políticos, poetas e vários reverendos, todos com formação acadêmica em Harvard. ${ }^{1}$ Após o exame oral, no qual Wheatley foi aprovada sem reservas, o grupo emitiu um documento atestando que a jovem negra, recém-vinda de terras bárbaras da África, possuía realmente aptidão para escrever tais poemas.

No entanto, mesmo com o aval do grupo, Phillis Wheatley não conseguiu apoio financeiro para publicar seus textos. A publicação só aconteceu em Londres, em 1773, com o apoio financeiro da condessa de Huntington, conhecida por apoiar a causa abolicionista. Wheatley tornouse, assim, a primeira mulher de descendência negra a publicar um livro de poemas e ganhar prestígio internacional, marcando, dessa forma, o início de uma tradição literária afro-americana. ${ }^{2}$ Embora desconhecida em Boston, a publicação em Londres lhe pôs em contato com importantes figuras do mundo literário, eclesiástico e político, fatos que contribuíram para sua liberdade após o retorno a Boston. Porém, isso em nada facilitou a aceitação de seus poemas nos Estados Unidos. Somente em 1788 seu livro ganharia uma publicação em terras estadunidenses.

\footnotetext{
${ }^{1}$ GATES. The Trials of Phillis Wheatley: America's First Black Poet and her Encounter with the Founding Fathers, p. 5.

${ }^{2}$ GATES. The Trials of Phillis Wheatley: America's First Black Poet and her Encounter with the Founding Fathers, p. 31.
} 
Em Poems on Various Subjects, Religious and Moral, Wheatley publica elegias cristãs, além de poemas sobre política, patriotismo, religião, moralidade, natureza, imaginação e memória. O livro também contém uma tradução para o inglês de Metamorfose, de Ovídio, do latim. No entanto, o que se destaca é seu uso extensivo de tropos, mitos e outros elementos da tradição clássica grega e latina, além da Bíblia, o que demonstra que Wheatley era muito familiarizada com a poética clássica de Homero, Ovídio, Virgílio e Pope. ${ }^{3}$ Esse uso extenso da tradição literária ocidental custou-lhe pesadas críticas ao longo dos anos, tanto por parte de escritores e intelectuais brancos quanto negros. Já em seus dias, o estadista Thomas Jefferson foi incisivo em sua crítica aos poemas de Wheatley, os quais via como derivativos do ponto de vista estético, fruto da religiosidade negra e sem qualidade artística alguma. Ao longo do século XX, escritores negros como James W. Johnson e Richard Wright a condenaram por não ter tematizado de forma mais incisiva a situação opressora em que viviam os negros. Críticos da geração dos anos 1960 e 1970, no embalo do Civil Rights Movement e Black Power Movement, também não se impressionaram com seus versos. Eleanor Smith, por exemplo, ecoando Wright, Johnson e tantos outros antes dela, afirma que Wheatley, por ter passado toda a sua vida entre pessoas brancas, sempre abraçou uma ideologia eurocêntrica. Consequentemente, nunca se posicionou ou "se sensibilizou com as necessidades de seu povo e nem demonstrou afinidade com os Negros em sua vida ou escritos". ${ }^{4}$ Ela é acusada de assimilacionismo e indiferença pela causa do povo negro.

Nas últimas décadas, no entanto, várias vozes têm se levantado em defesa de Wheatley, especialmente salientando seu engajamento com questões cruciais de seu tempo, como a colonização britânica, a opressão dos povos nativos e, é claro, a escravidão de negros. Críticos têm ressaltado que Wheatley foi estratégica no uso de suas habilidades artísticas. Isto é, por um lado, ela abraça a tradição poética clássica como forma de dar um tom de credibilidade a seus escritos e, com isso, ganhar acesso ao público branco e letrado; por outro, ela usa sua arte como instrumento para confrontar importantes vozes do mundo filosófico,

\footnotetext{
${ }^{3}$ DOVELL. The Interaction of the Classical Traditions of Literature and Politics in the Work of Phillis Wheatley, p. 35-36.

4 "sensitive to the needs of her own people to demonstrate a kinship to Blacks in her life or writings" (SMITH. Phillis Wheatley: a Black Perspective, p. 403, tradução minha).
} 
religioso e político da época. A crítica recente também tem salientado o aspecto vindicador de sua produção poética, isto é, a forma como seus poemas defendem e colocam em evidência, embora sutilmente na maioria das vezes, a cultura e a tradição afrodescendente. Na verdade, Larose T. Parris observa, as críticas negativas a produções culturais como as de Wheatley serviram para fomentar o surgimento de movimentos entre escritores negros com o intuito de promulgar a humanidade e capacidade intelectual dos afrodescendentes. Foi o início, reitera Parris, de movimentos de vindicação da cultura e identidade negra na forma de obras literárias e outras expressões artísticas. ${ }^{5}$ Os poemas de Wheatley se constituem, nessa perspectiva, uma das primeiras manifestações literárias visando vindicar a humanidade negra.

É em diálogo com essas perspectivas críticas mais recentes que este ensaio examinará o modo como Wheatley interroga visões de raça, nação e alteridade, disseminadas por importantes figuras do Iluminismo e Cristianismo protestante, duas correntes ideológicas muito influentes no cenário político-cultural estadunidense do século XVIII. O objetivo é salientar o viés vindicativo de sua obra e mostrar que seus poemas, longe de serem apenas exercícios de imitação poética e expressões de assimilação cultural, demonstram um engajamento, ora sutil, ora mais aberto, com questões transformadoras que movimentavam o cenário intelectual e político de seu tempo. Para fins de argumentação e análise, este ensaio se concentrará em três poemas nos quais suas posições em relação a questões de nação, raça e identidade são mais evidentes: "On Being Brought from Africa to America", "To the University of Cambridge, in New England" e "To the Right Honorable William, Earl of Dartmouth".

\section{Nação, raça e alteridade: contextualizando a poesia de Wheatley}

Pode-se afirmar que o conflito nação versus raça constitui um dos principais eixos temáticos em Poems on Various Subjects. Esse conflito ganha complexidade quando colocado contra o pano de fundo religioso e filosófico dos Estados Unidos setecentistas. A poesia de Wheatley surge, dessa forma, da confluência de três elementos em constante tensão em seu tempo: nação, raça e religião. Apesar dos entraves sociais que a limitavam, ela consegue fazer da poesia um

\footnotetext{
${ }^{5}$ PARRIS. Being Apart: Theoretical and Existential Resistance African Literature, p. 4.
} 
poderoso instrumento para questionar preceitos filosóficos e religiosos que denegriam os afrodescendentes ao desqualificá-los como seres racionais, autônomos e capazes de participar do projeto de nação em formação. Joana Brooks utiliza a metáfora bíblica do Lázaro ressuscitado para descrever como escritores afrodescendentes do século XVIII nos Estados Unidos venceram a morte social ao criarem literatura capaz de intervir no espirito nacionalista e iluminista que dominava a nação em formação. Por meio da literatura e outras intervenções culturais, como um Lázaro Americano ressuscitado, homens e mulheres criaram novas identidades, comunidades e tradições, apesar da colonização e escravidão que lhes tiravam a vida, muitas vezes literalmente. ${ }^{6}$ A metáfora do Lázaro ressurreto é apropriada para descrever o papel de Wheatley no surgimento da literatura afrodescendente nos Estados Unidos. Fisicamente frágil e socialmente morta, Wheatley ressurge como uma voz importante de afirmação racial e intervenção cultural no cenário político dos Estados Unidos setecentistas.

Wheatley escreveu em um período no qual intelectuais ligados tanto ao clero quanto a movimentos políticos e filosóficos vituperavam o sujeito negro, questionando se indivíduos de ascendência africana tinham capacidade racional para criar, desenvolver e articular visões de mundo sofisticadas por si mesmos. Para sustentar essa concepção, a elite intelectual e religiosa dos Estados Unidos setecentistas bebia, principalmente, nas fontes dos pensadores iluministas europeus, entre os quais não faltavam teorizações visando demonstrar a superioridade dos povos brancos. O Iluminismo, pautado em valores como objetividade, razão e hierarquia natural, via o povo negro como uma raça sem os atributos característicos do mundo civilizado. O filósofo escocês David Hume, em Ensaios morais, políticos e literários, dizia, por exemplo, que pessoas de compleição negra eram "naturalmente inferiores aos brancos", pois nunca houve entre estes "sequer um indivíduo eminente seja na ação, seja na especulação". ${ }^{7}$ Para ele, a própria natureza havia feito uma "distinção original" entre negros e outros povos, fato que justificava não haver entre estes povos arte, ciência ou engenhosidade. ${ }^{8}$ Como filósofo

\footnotetext{
${ }^{6}$ BROOKS. American Lazarus: Religion and the Rise of African-American and Native American Literatures, p. 3-6.

${ }^{7}$ HUME. Ensaios morais, políticos e literários, p. 344.

${ }^{8}$ HUME. Ensaios morais, políticos e literários, p. 344.
} 
empirista, Hume defendia que o conhecimento era fruto da experiência, isto é, do modo como os sentidos apreendiam e como a mente processava o mundo ao redor. As ideias, das mais simples às mais complexas, eram frutos de apreensões sensoriais do mundo, que se tornavam preceitos após um processo de intelectualização - estabelecimento de relações e comparações entre diferentes tipos de impressões. O negro, para Hume, possuía capacidade cognitiva, já que podia fazer distinções e aprender coisas rudimentares. No entanto, não passava da fase de recepção passiva de impressões externas, pois lhe faltava a capacidade inata de abstrair, estabelecer relações e fazer generalizações. ${ }^{9}$ Do ponto vista ontológico, a inferioridade dos negros era inerente, natural. Em um período em que a razão estava no centro das discussões sobre nação, ciência, arte e política, ser destituído dessa capacidade significava ser sub-humano, acima talvez apenas das bestas do campo.

Alguns anos mais tarde, o filósofo alemão Immanuel Kant veio reforçar essas observações de Hume. Se este especulava a respeito das diferenças culturais em termos de língua e comportamento, Kant se interessava pelas reações de diferentes nacionalidades ao que denominava de belo e sublime. Semelhante a Hume, Kant elenca várias nacionalidades, tais como alemães, franceses, italianos, espanhóis e ingleses, mostrando como estes reagiam diante de manifestações do sublime ou do belo. Neste quesito, "os negros da África", observa Kant, não "possuem, por natureza, nenhum sentimento que se eleve acima do ridículo". Ele prossegue, por ora parafraseando Hume em muitos aspectos, afirmando que, mesmo após longa convivência entre brancos, não havia visto progresso cultural e científico entre negros. Por fim, observa: "Tão essencial é a diferença entre essas duas raças humanas, que parece ser tão grande em relação às capacidades mentais quanto à diferença de cores".${ }^{10} \mathrm{O}$ que se destaca tanto em Hume quanto em Kant é a ênfase na dicotomia natureza versus civilização. Para ambos, havia uma diferença genética entre brancos e negros, razão pela qual estes estavam fadados a permanecer num estado constante de menoridade intelectual, em outras palavras, incivilizados. Importante também é a ênfase no termo "nação". O título da seção na qual Kant faz suas observações é "Dos caracteres nacionais", semelhante a Hume que também conecta essas qualidades ao sentimento de nação.

${ }^{9}$ EZE. Hume, Race, and Human Nature, p. 695.

${ }^{10}$ KANT. Observações sobre o sentimento do belo e do sublime, p. 75-76. 
Dessa forma, como povo, os negros são completamente excluídos do projeto iluminista do ponto de vista artístico, linguístico e científico. Outros iluministas, como o francês François-Marie Arouet, mais conhecido como Voltaire, o inglês John Locke e o alemão Georg W. F. Hegel demonstravam visões parecidas em relação ao negro. Voltaire foi adiante, inclusive, ao defender uma visão poligenista da origem humana. Afirmava que negros e índios vieram de progenitores diferentes dos da raça branca, pré-adâmicos, tal a disparidade física e intelectual que via entre esses dois grupos.

Nos Estados Unidos, esse racismo científico ganhou novas dimensões nas observações de Thomas Jefferson, principal autor da declaração de independência e terceiro presidente dos Estados Unidos. Em Notes on the State of Virginia (1781), ele comenta que os negros eram em muitos aspectos mais corajosos que os brancos, que tinham certas habilidades musicais, mas duvidava que fossem capazes de aprender melodias mais complexas. Como Hume e Kant, ele também dizia que os negros eram mais ligados às sensações do que à reflexão, razão essa pela qual preferiam dormir após uma jornada de trabalho. Venciam também facilmente períodos de aborrecimento, distraindo-se facilmente com qualquer atividade lúdica: "Aquelas inúmeras aflições que nos fazem interrogar se o céu nos deu vida por misericórdia ou ódio, são menos sentidas e por eles e logo esquecidas". ${ }^{11}$ Em relação à memória não diferiam muito dos brancos, mas quanto à razão e imaginação, eram claramente inferiores. Ele observa nunca ter visto um negro expressar um pensamento sequer acima do nível da narração simples, razão essa por não existir poetas entre os negros. Ele conclui uma longa linha de raciocínio, observando que se a escassez de comida ou afeto serviu de inspiração para muitos poetas, entre os negros, onde a miséria abundava, não havia produzido arte. Nem mesmo a religião cristã foi capaz de afetar o espírito criativo dos negros. Foi nesse contexto, inclusive, que ele usa os escritos de Wheatley como exemplo da incapacidade intelectual dos negros: "[A] religião foi capaz de produzir uma Phillis Wheatley; mas não foi capaz de produzir uma poeta. As composições publicadas

11 "Those numberless afflictions, which render it doubtful whether heaven has given life to us in mercy or in wrath, are less felt, and sooner forgotten by them" (JEFFERSON. Notes on the State of Virginia, p. 264, tradução minha). 
sob seu nome não são nem mesmo dignas de crítica". ${ }^{12}$ Uma afirmação dessa natureza partindo de um pensador da estatura de Jefferson teria efeitos prolongados no imaginário da elite branca estadunidense, a qual, fortemente influenciada por leituras racistas da Bíblia, já via os negros como seres amaldiçoados por Deus.

Percepções de raça como as de Jefferson, regadas pela ideologia iluminista, ganhariam novo fôlego e formas distintas ao confluir com a narrativa bíblica de povo escolhido ou o mito israelita, base ideológica que sustentava o projeto colonialista e expansionista estadunidense. Com base no mito de nação e povo escolhido, os colonizadores viam-se, desde os primórdios da colonização norte-americana, como os israelitas modernos libertados por Deus dos inimigos da fé cristã no velho mundo - o Egito moderno - e trazidos para se estabelecer no novo mundo. $\mathrm{Na}$ América, eles teriam a tão sonhada liberdade religiosa e política, construiriam a nova Jerusalém dos tempos modernos, destinada a ser uma luz moral e política para o mundo. Os colonizadores se apropriam, dessa forma, da tipologia bíblica do Êxodo ao imaginar a travessia pelo oceano, a chegada em terras estranhas e a revolução Americana, inclusive, como o cumprimento de profecias veterotestamentárias. ${ }^{13}$ Nesse contexto, o negro escravo veio fortalecer ainda mais essa cosmovisão, pois o cristianismo protestante, numa tentativa de explicar a origem das raças, os via como tendo sua origem na ira divina. Alguns viam a negritude como a marca que Deus havia colocado sobre Caim por ter assassinado seu irmão Abel. Embora a Bíblia não especifique o tipo de marca, a maioria dos cristãos assumiu ser a cor negra o sinal de Deus para distinguir os descendentes de Caim do restante dos filhos de Adão. Outros viam a escravidão e negritude como tendo origem na maldição de Cam, o qual, segundo o relato bíblico, teve sua posteridade amaldiçoada ao ver seu pai Noé despido. Canaã, seu filho, além de supostamente ter se tornado negro, foi amaldiçoado a ser servo para sempre, tanto ele como sua posteridade. Como Cam e seus descendentes povoaram o norte da África, logo se estabeleceu que

\footnotetext{
12 "Religion indeed has produced a Phyllis Whately [sic]; but it could not produce a poet. The compositions published under her name are below the dignity of criticism" (JEFFERSON. Notes on the State of Virginia, p. 267, tradução minha).

${ }^{13}$ GLAUDE. Exodus: Religion, Race, and Nation in Early Nineteenth-Century Black America, p. 46.
} 
os africanos eram descendentes naturais de Cam, destinados a ser cativos através da maldição de Noé. ${ }^{14}$

Dessa forma, a construção do negro como o Outro ganhou força e contornos próprios no imaginário ante e pós-revolução americana, numa confluência perniciosa entre teologia e pseudociência. Na concepção teológica de nação e povo escolhido, o que se promulgava era a identidade divina do colonizador euro-americano vis-à-vis a origem amaldiçoada do negro africano, o qual, para alguns, era descendente de Cam, para outros, descendente de Caim. Independente da origem, o fato era que em ambas as concepções, os africanos eram herdeiros de uma maldição divina, destinados ao subdesenvolvimento e servidão eterna. Negar isso seria negar a própria Bíblia, tida como fonte mor de sabedoria divina para os colonizadores. Nesse contexto, a escravização do negro nada mais era do que o cumprimento de profecias bíblicas. O racionalismo iluminista, ao agregar uma aura de objetividade e cientificismo a essa percepção do negro, solidificaria a visão do africano como ser supostamente inferior. Médicos, antropólogos e etnógrafos se apressaram a provar objetivamente, através de análises de crânio, fenótipo e outras características físicas, a inferioridade natural do negro.

\section{Vindicação e resistência na poesia de Wheatley}

O combate tanto ao racismo científico quanto ao discurso teológico que defendia a superioridade do euro-americano pode ser percebido em vários poemas de Wheatley. Ela tematiza de forma incisiva essa vindicação da humanidade negra, por exemplo, em dois poemas bem conhecidos da crítica contemporânea: "On Being Brought from Africa to America" e "To the University of Cambridge, in New England". ${ }^{15}$ Em ambos os poemas, ela confronta preceitos do Iluminismo e protestantismo anglo-saxão ao questionar os binários que relegavam o sujeito negro à categoria de Outro, inferiorizado e amaldiçoado: América-África, branconegro, cristão-pagão, salvação-perdição e civilizado-primitivo. Ela questiona principalmente noções essencialistas de nação, raça e cidadania ao não se intimidar frente ao poder vigente, representado em "To the

${ }^{14}$ JOHNSON. The Myth of Ham in Nineteenth-Century American Christianity: Race, Heathens, and the People of God, p. 27-28.

${ }^{15}$ Poemas traduzidos por mim. 
University of Cambridge" pelos jovens acadêmicos da universidade e em "On Being Brought from Africa to America" pela comunidade protestante da Nova Inglaterra.

Escrito em oito versos em forma de dístico, "On Being Brought from Africa to America" é estruturado como se a poeta estivesse respondendo a um questionamento: Deus estenderia sua compaixão e salvação a uma pessoa de origem africana? Ou melhor, com base no conceito calvinista de eleição, cerne do protestantismo nas colônias norte-americanas, Deus estenderia as bênçãos da eleição a alguém vindo de uma herança amaldiçoada? Segundo o poema, a resposta é afirmativa. Aqui, a concepção de um Deus implacável é substituída pela de um compassivo. Diz o poema: "Foi a misericórdia que me trouxe de uma terra Pagã / Que ensinou minha alma ignorante a entender, / Que há um Deus, e um Salvador também". ${ }^{16}$ Logo nos primeiros versos, ela já mostra que sua cor não impediu a misericórdia divina de alcançá-la. Muitos críticos têm lido esses versos como uma aceitação e ratificação por parte da poeta da visão eurocêntrica da África como um continente atrasado e mergulhado nas trevas tanto social quanto espiritualmente. Nessa visão, para o europeu, trazer o negro para a civilização, ainda que na condição de escravo, constituía um ato de nobreza e amor cristão. ${ }^{17}$ Embora essa interpretação dos versos iniciais seja possível, eles também sugerem uma rejeição da visão de um Deus que elege uns e relega outros, sem explicação, à perdição eterna. Ao salientar o fator misericórdia, Wheatley se coloca em pé de igualdade com os outros que fizeram a mesma travessia pelo Atlântico tal qual ela fez. Isto é, ela coloca em xeque a noção do euro-americano como povo eleito ao se posicionar como igualmente receptora das mesmas bênçãos ou promessas divinas.

Desse modo, Wheatley inicia o poema minando o conceito teológico calvinista de eleição divina, base que sustentava o projeto nacionalista estadunidense. Nos versos seguintes, ela aprofunda essa crítica mais ainda ao confrontar signos e interpretações bíblicas utilizadas convenientemente para negar a humanidade dos africanos. Um conceito típico do protestantismo calvinista era a noção da expiação limitada,

\footnotetext{
16 "Twas mercy brought me from a Pagan land, / Taught my benighted soul to understand, / That there's a God, that there's a Saviour too" (WHEATLEY. On Being Brought from Africa to America, p. 98).

${ }^{17}$ CALLAHAN. The Talking Book: African Americans and the Bible, p. 26.
} 
segundo a qual o sacrifício expiatório de Cristo só alcançaria aqueles já escolhidos por Deus. Nessa visão, alguns estariam predestinados à salvação e outros à perdição eterna. Os negros africanos estavam, naturalmente, nesta última categoria. John Winthrop, em A Model of Christian Charity, por exemplo, fez o seguinte registro: "O Deus Poderoso em sua mais divina e sábia providência, assim dispôs as condições da humanidade, em certos tempos alguns devem ser ricos, alguns pobres, alguns em posições elevadas e eminentes de poder e dignidade; outros medianos e sob sujeição". ${ }^{18}$ Aqui, Winthrop expõe valores calvinistas de submissão e obediência como parte natural da existência para determinadas pessoas, condição essa sobre a qual o indivíduo não tem controle. No caso do colonizador europeu, como um novo Adão, eles estavam predestinados a desbravar uma terra selvagem para ali construir uma nova civilização. Ao dizer que há um Deus e um Salvador também, Wheatley coloca em oposição um Deus que limita e escolhe a quem estender sua misericórdia e um Salvador misericordioso que age segundo o coração. No contexto bíblico, salvador é aquele que resgata, tal qual fez Deus ao libertar os israelitas cativos no Egito. Ela retoma o conceito bíblico de redenção - o livramento de alguém de uma obrigação ou condição social de submissão -, trazendo-o para seu contexto de escrava em terras estranhas, local onde aguarda redenção espiritual e temporal.

Nos versos seguintes, ela elabora sua crítica ao confrontar teorias que associavam a cor negra a uma maldição passada, sem chances de reversão, nem mesmo pelo sacrifício expiatório de Cristo. Segundo os preceitos de expiação limitada, essa promessa salvífica não alcançava os africanos e seus descendentes, já que predominava, nos Estados Unidos setecentistas, a visão de que a negritude era sinal de maldição irreversível. Além do mais, a essas passagens bíblicas eram acrescentadas as cartas do apóstolo Paulo, o qual parecia apoiar a instituição escravocrata ao ensinar que a obediência irrestrita aos senhores fazia parte da jornada terrestre, para alguns pelo menos. Cam, Caim e as cartas paulinas se tornariam assim o leitmotiv que dominaria os discursos pró-escravidão nos Estados Unidos setecentistas. ${ }^{19}$ Além disso, a concepção de que o

\footnotetext{
18 "God Almighty in his most holy and wise providence, hath so disposed the condition of mankind, as in all times some must be rich, some poor, some high and eminent in power and dignity; others mean and in subjection" (WINTHROP. A Model of Christian Charity, p. 95).

${ }^{19}$ CALLAHAN. The Talking Book: African Americans and the Bible, p. 30.
} 
diabo era negro fazia parte do folclore colonialista, embora sem nenhum respaldo em passagens bíblicas. Cotton Mather, por exemplo, em The Wonders of the Invisible World, alertava os moradores da Nova Inglaterra a se precaverem contra as artimanhas do diabo, cuja missão era destruir o projeto de nação em formação. No período do julgamento das bruxas de Salem, Massachusetts, entre os anos de 1692 e 1693, ele exortava: "O diabo, manifestando-se comumente com um homem negro pequeno, atraiu um grupo assustador de criaturas maliciosas, invejosas, ignorantes e orgulhosas a se alistarem ao seu serviço de horror" ${ }^{20} \mathrm{Na}$ verdade, a cor negra era usada para descrever qualquer coisa de aparência maligna, desde animais a visões em sonho.

Wheatley está ciente dessa percepção de sua cor: "Alguns veem nossa raça negra com olhos de escárnio / 'A cor deles é de origem diabólica"". ${ }^{21}$ Porém, longe de aceitá-la, ela confronta a visão na qual a condição social e espiritual do negro se constituía algo irreversível: "Lembrem-se, Cristãos, Negros, escuros como Caim, / Podem ser refinados, e juntarem-se ao cortejo angelical". ${ }^{22}$ Nesses versos ela demonstra sua rejeição do princípio do inatismo, perspectiva segundo a qual o negro já nascia fadado ao subdesenvolvimento e à marginalização. Ao afirmar que o africano pode ser refinado e fazer parte dos eleitos, ela abraça uma perspectiva não essencialista da condição humana, enfatizando o papel do ambiente na formação de um indivíduo. Ela faz alusão aqui à visão lockeana questionadora da noção inatista do conhecimento e desenvolvimento humano. John Locke defendia a tese de que são as experiências na sociedade que formam o indivíduo e não uma condição determinante a priori. Se na visão do sistema escravagista o negro estava fadado à ignorância espiritual e, consequentemente, à exclusão social, ao destacar que os africanos poderiam ser refinados, ela confronta, nas palavras de Elizabeth J. West, tanto as presunções de exclusividade branca quanto suas interpretações racistas das escrituras. ${ }^{23}$

${ }^{20}$ SMOLINSKI. The Wonders of the Invisible World: Observations as Well Historical as Theological, upon the Nature, the Number, and the Operations of the Devils (1693), p. 37. 21 "Some view our sable race with scorful eye, / "Their colour is a diabolic die"" (WHEATLEY. To the University of Cambridge, in New-England, p. 98).

22 “'Remember, Christians, Negros, black as Cain, / May be refin'd and join th' angelic train" (WHEATLEY. To the University of Cambridge, in New-England, p. 98).

${ }^{23}$ WEST. African Spirituality in Black Women's Fiction: Threaded Visions of Memory, Community, Nature, and Being, p. 3. 
Wheatley mostra que os negros como Caim poderiam, sim, fazer parte do projeto de nação, desde que as condições para tal lhes fossem proporcionadas. A tipologia bíblica "cortejo angelical", nesse caso, é manipulada, significando não apenas a entrada para a congregação dos cristãos, mas também participação no projeto de nação estadunidense.

Se em "On Being Brought from African to America" o objetivo da poeta é desconstruir noções teológicas de raça e providência divina, em "To the University of Cambridge, in New-England" o que fica mais evidente é um discurso de autoafirmação, de negociação identitária e de resgate da dignidade africana em meio aos discursos científicos que a denegriam. Como no poema anterior, os versos iniciais parecem demonstrar aceitação de estereótipos da África como "A terra de erros, a trevas Egípcia", ${ }^{24}$ da qual ela foi tirada por misericórdia e não por força. No entanto, logo em seguida, o tom de aparente submissão muda, e Wheatley assume o controle da elocução. Primeiramente, ela expõe seu conhecimento das disciplinas por eles estudadas nos bancos acadêmicos - ciências e astronomia: "Estudantes, a vós é dado perscrutar as alturas / Atravessar o espaço sideral / E marcar os sistemas de mundos que giram / Ainda mais, vós filhos da ciência...". ${ }^{25}$ Conhecedora dos debates entre religião e ciência travados nos meios acadêmicos, ela urge os estudantes a não se deixaram iludir pelo racionalismo exacerbado e o pecado da arrogância e do orgulho. Ela lembra-lhes que foi essa atitude de arrogância que levou os primeiros seres criados a confrontar seu criador: "Que o pecado, esse mal nefasto para alma / Seja por vós evitado, nem um só momento baixem vossa guarda; / Esmaguem a serpente mortal ainda em seu embrião". ${ }^{26}$ A alusão à serpente do Éden evidencia sua intenção de mostrar a conexão perigosa entre conhecimento e arrogância.

Porém, o que mais chama a atenção no poema é o modo como Wheatley se posiciona em relação a esse grupo de universitários. Longe de se intimidar diante do elevado grau de conhecimento destes, ela impõe sua

24 "The land of errors, and Egyptian gloom" (WHEATLEY. To the University of Cambridge, in New-England, p. 98).

25 "Students, to you 'tis giv'en to scan the heights / Above, to traverse the ethereal space, / And mark the systems of revolving worlds. / Still more, ye sons of science..." (WHEATLEY. To the University of Cambridge, in New-England, p. 98).

26 "Let sin, that baneful evil to the soul, / By you by shunn'd, nor once remit your guard; / Suppress the deadly serpent in its egg" (WHEATLEY. To the University of Cambridge, in New-England, p. 98). 
voz e destaca a importância da precaução espiritual e, mais importante, ressalta suas origens africanas ao invocar o termo "etíope": "Uma Etíope lhes diz que é seu pior inimigo; / Sua doçura transitória se transforma em dor sem fim, / E em perdição eterna afunda a alma". ${ }^{27}$ Ao intitular-se etíope, ela faz um movimento político e traz para o contexto do poema a agenda do movimento que ficaria conhecido no século XVIII e XIX como Etiopianismo. O Etiopianismo emergiu nas colônias norte-americanas como uma mobilização política e religiosa, cujo objetivo era combater os estereótipos de inferioridade propagados pelo discurso protestante e iluminista. Como movimento nacionalista, o Etiopianismo ligava a África a um passado glorioso, contrário a descrições do continente destituído de história e mergulhado na ignorância. Os defensores apontavam que a própria Bíblia, usada pelos escravagistas para justificar a escravidão do africano, estava cheia de menções a etíopes ligados a personagens bíblicos importantes: Moisés se casou com uma etíope; ${ }^{28}$ o rei Salomão teve um encontro com a rainha de Sabá, nome antigo para Etiópia, a qual veio visitá-lo acompanhada de uma grande comitiva, cheia de riquezas e de pedras preciosas. ${ }^{29}$ Dessa forma, o Etiopianismo visava apropriar-se do passado e reescrever a história de modo a exaltar as civilizações africanas mencionadas na Bíblia como egípcios e etíopes. ${ }^{30}$ Alguns chegavam até a imaginar um futuro onde a África controlaria o mundo, tal como descrito no salmo de Davi: "Príncipes virão do Egito; a Etiópia cedo estenderá para Deus as suas mãos". ${ }^{31}$ Nesse salmo, o rei Davi imagina um dia em que os hebreus da diáspora retornariam a Jerusalém e adorariam a Deus na terra de seus ancestrais.

Com base nestas e outras passagens, os etiopianistas se viam como herdeiros de uma promessa divina e não uma raça amaldiçoada. Se ser etíope no discurso anglo-americano denotava escravidão e maldição, no etiopianismo apontava para esperança e redenção. Portanto, em "To the University of Cambridge, in New-England”, Wheatley se mostra consciente

27 “An Ethiop tells you 'tis your greatest foe; / Its transient sweetness turns to endless pain, / And in immense perdition sinks the soul" (WHEATLEY. To the University of Cambridge, in New-England, p. 98).

${ }^{28}$ Números. 12:1.

${ }^{29}$ Reis 10:1-13.

${ }^{30}$ PAINTER. Creating Black Americans: African-American History and its Meanings, 1619 to the present, p. 6.

${ }^{31}$ Salmos 68:31. 
das implicações políticas do termo "etíope", principalmente por estar se dirigindo a um grupo de acadêmicos, os quais com certeza tinham muitas reservas em relação a sua capacidade intelectual. $\mathrm{O}$ mundo acadêmico certamente já os havia exposto à literatura que denegria os africanos. Ao posicionar-se como poeta e como negra, Wheatley se coloca em pé de igualdade, fazendo-os lembrar de que seus antepassados construíram grandes civilizações, como, por exemplo, a do Egito. O poema transformase, assim, num discurso de construção e afirmação identitária em um universo onde ela e seus compatriotas eram vistos com desprezo.

Esse discurso de autoafirmação e resgate da sua história continua no poema "To the Right Honourable William, Earl of Dartmouth". O ponto interessante deste poema está no fato de ela usar a situação política das colônias americanas como o pano de fundo para seu discurso de liberação. $\mathrm{O}$ conde de Dartmouth havia sido selecionado para governar os assuntos da Nova Inglaterra em um tempo de turbulência política, principalmente devido à recusa das colônias em pagar impostos à coroa britânica. Por simpatizar com a causa das colônias, ele era visto como um defensor da causa da liberdade da nação em formação. Assim, o poema é escrito em forma de agradecimento dos habitantes da Nova Inglaterra pelo apoio a tão sonhada liberdade: "Não mais, America, em tensão e luto / Reclamarás pelos erros e males sofridos / Não mais temerás a corrente de ferro / A qual a Tirania devassa construiu com mãos sem lei / E com ela desejou escravizar a terra". ${ }^{32}$

Porém, o que se destaca no poema é o uso desse contexto de opressão colonial para trazer à tona sua condição de escrava e cativa. Aqui, ao contrário do que coloca em "On Being Brought from Africa to America", ela não retrata sua vinda à América como um ato de benevolência de um Deus misericordioso. Com um tom mais incisivo, ela diz que foi arrancada de seu lar africano, deixando para trás uma família em luto pela perda da filha: "Eu, jovem na vida, por um destino cruel semelhante / Fui apanhada de um lugar feliz na África: / Que excruciante dor deve ter sido / Que tristezas profundas no coração de meus

32 "No more, America, in mournful strain / Of wrongs, and grievance unredress'd complain, / No longer shalt thou dread the iron chain, / Which wanton Tyranny with lawless hand / Had made, and with it meant t' enslave the land" (WHEATLEY. To the Right Honourable William, Earl of Dartmouth, p. 100). 
pais?". ${ }^{33}$ Ela prossegue imaginando o trauma da separação, chamando de coração de ferro quem cometeu tamanha atrocidade: "Alma de aço foi quem arrancou / sem misericórdia a filha querida dos braços do pai". ${ }^{34}$ Ela encerra esta seção do poema dizendo ter experiência para falar de opressão e sofrimento: "Tal, tal é minha situação. E como posso eu senão orar / Para que outros não tenham o mesmo destino?". ${ }^{35}$

Ela usa, assim, o contexto político de opressão das colônias americanas para falar de sua condição passada, especialmente de como era feliz e livre, em contraste com sua situação atual de escrava, na qual sua voz e movimentos são limitados. Ao assemelhar sua condição de cativa à condição das colônias em relação à Inglaterra, Wheatley se apropria das ferramentas do opressor, neste caso a língua e a tradição literária, para apontar não só a sua condição de servitude, como também a de milhares de africanos que povoavam a colônia. Ela exalta as vicissitudes do conde e seu poder de intervir em favor da colônia, mas no processo entrega também seu recado ao denunciar o modo desumano como os africanos eram trazidos e mantidos cativos na América.

\section{Observações finais}

A produção poética de $\mathrm{Phillis}$ Wheatley, embora tenha o reconhecimento da crítica contemporânea devido ao comando da métrica e do estilo clássico, tem encontrado também forte resistência. Segundo seus opositores, ela poderia ter usado melhor os privilégios que tinha em seu caso, o letramento - para denunciar a condição desumana à qual os negros escravos eram submetidos diariamente.

Não se pode negar que há, de fato, certa ambivalência nos poemas de Wheatley em relação ao tema da escravidão. Porém, quando se examina com mais cuidado vários de seus poemas, como os acima analisados, percebe-se que ela não era indiferente à questão do tráfico e exploração da mão de obra escrava para fins econômicos. É possível

\footnotetext{
33 "I, young in life, by seeming cruel fate / Was snatch'd from Afric's fancy'd happy seat: / What pangs excruciating must molest, / What sorrows labour in my parent's breast?" (WHEATLEY. To the Right Honourable William, Earl of Dartmouth, p. 100). 34 "Steel'd was that soul and by no misery mov'd / That from a father seiz'd his babe belov'd" (WHEATLEY. To the Right Honourable William, Earl of Dartmouth, p. 100). 35 "Such, such my case. And can I but pray /Others may never feel tyrannic sway?" (WHEATLEY. To the Right Honourable William, Earl of Dartmouth, p. 100).
} 
notar que sempre que a oportunidade lhe permitiu, ela soube fazer de seus versos um instrumento de contestação de percepções dos negros como seres inferiores.

Esse posicionamento, ora dissimulado, ora visível, faz de seus poemas um dos primeiros exemplos, na América do Norte, do uso da literatura como instrumento de vindicação e oposição ao discurso eurocêntrico de demonização e inferiorização do afrodescendente. Se o ato de escrever versos, por si só, já constituía uma contestação dos estereótipos que associavam os negros à inferioridade intelectual e cultural, ao mencionar suas origens africanas, Wheatley dá um passo à frente. Ela usa seus versos para criar uma identidade diferente daquela a ela atribuída pelo colonizador. Com isso, seus poemas tornam-se instrumentos não apenas de denúncia e vindicação cultural, mas também de afirmação identitária e valorização de suas raízes e da tradição africana.

\section{Referências}

BÍBLIA, A. T. Bíblia de estudo de Genebra: antigo e novo testamentos. Tradução de João Ferreira de Almeida. Sociedade Bíblica do Brasil, 1998.

BROOKS, Joanna. American Lazarus: Religion and the Rise of AfricanAmerican and Native American Literatures. New York: Oxford University Press, 2003.

CALLAHAN, Allen D. The Talking Book: African Americans and the Bible. New Haven: Yale University Press, 2006.

DOVELL, Karen L. The Interaction of the Classical Traditions of Literature and Politics in the Work of Phillis Wheatley. In: SHIELDS, John C., LAMORE, Eric D. (Org.). New Essays on Phillis Wheatley. Knoxville: The University of Tennessee Press, 2011. p. 35-36.

EZE, Emmanuel C. Hume, Race, and Human Nature. Journal of the History of Ideas, v. 61, n. 4, p. 691-698, 2000. doi: https://doi.org/10.1353/ jhi.2000.0039

GATES, Henry Louis, Jr. The Trials of Phillis Wheatley: America's First Black Poet and her Encounter with the Founding Fathers. New York: Basic Books, 2010. 
GLAUDE, Eddie S., Jr. Exodus: Religion, Race, and Nation in Early Nineteenth-Century Black America. Chicago: The University of Chicago Press, 2000.

HUME, David. Ensaios morais, políticos e literários. Tradução de Luciano Trigo. Rio de Janeiro: Topbooks, 2004.

JEFFERSON, Thomas. Notes on the State of Virginia. In: PETERSON, Merrill D. (Org.) Jefferson: Writings. New York: Literary Classics of the United States, 1984. p. 264-267.

JOHNSON, Sylvester A. The Myth of Ham in Nineteenth-Century American Christianity: Race, Heathens, and the People of God. New York: Palgrave Macmillan, 2004.

KANT, Immanuel. Observações sobre o sentimento do belo e do sublime. Tradução de Vinicius de Figueiredo. Campinas: Papirus, 1993.

PAINTER, Nell I. Creating Black Americans: African-American History and its Meanings, 1619 to the present. New York: Oxford University Press, 2006.

PARRIS, Larose, T. Being Apart: Theoretical and Existential Resistance African Literature. Charlottesville: University of Virginia Press, 2015.

SMITH, Eleanor. Phillis Wheatley: a Black Perspective. The Journal of Negro Education, v. 43, p. 401-407, 1974. doi: https://doi. org/10.2307/2966531

SMOLINSKI, Reiner (Org.). The Wonders of the Invisible World: Observations as Well Historical as Theological, upon the Nature, the Number, and the Operations of the Devils (1693). Electronic Texts in American Studies. Lincoln: University of Nebraska, 1998. Disponível em: <https://digitalcommons.unl.edu/cgi/viewcontent. cgi? article $=1019 \&$ context $=$ etas $>$. Acesso em: 11 jun. 2018.

WEST, Elizabeth J. African Spirituality in Black Women's Fiction: Threaded Visions of Memory, Community, Nature, and Being. Lanham: Lexington Books, 2011.

WHEATLEY, Phillis. On Being Brought from Africa to America. In: HILL, Patricia L. (Ed.). Call and Response: the Riverside Anthology of the African American Literary Tradition. New York: Houghton Mifflin Company, 1997.p. 98 
WHEATLEY, Phillis. To the Right Honourable William, Earl of Dartmouth, His Majesty's Principle Secretary of State for North America. In: HILL, Patricia L. (Ed.). Call and Response: the Riverside Anthology of the African American Literary Tradition. New York: Houghton Mifflin Company, 1997.p. 100

WHEATLEY, Phillis. To the University of Cambridge, in New England. In: HILL, Patricia L. (Ed). Call and Response: the Riverside Anthology of the African American Literary Tradition. New York: Houghton Mifflin Company, 1997.p. 98

WINTHROP, John. A Model of Christian Charity. In: BAYN, Nina (Ed.). The Norton Anthology of American Literature. Sixth edition. New York: W. W. Norton \& Company, 2003. p. 95.

Recebido em: 15 de junho de 2018. Aprovado em: 19 de setembro de 2018. 